\title{
Decreased glomerular filtration rate is a significant and independent risk for in-hospital mortality in Japanese patients with acute myocardial infarction: report from the Hokkaido acute myocardial infarction registry
}

\author{
Hiroki Satoh ${ }^{1,2}$, Naoki Ishimori ${ }^{2}$, Mamoru Sakakibara ${ }^{2}$, Shiro Yamada $^{2}$, Nozomu Kawashima ${ }^{3}$, \\ Kazushi Urasawa ${ }^{4}$, Satoshi Fujiii ${ }^{5}$ and Hiroyuki Tsutsui ${ }^{2}$, on behalf of Hokkaido Acute Myocardial Infarction \\ Registry Investigators
}

Renal dysfunction is a significant risk factor in the prognosis of patients with cardiovascular diseases. We sought to determine the relationship between estimated glomerular filtration rate (eGFR) values and in-hospital mortality in Japanese acute myocardial infarction (AMI) patients. A total of 2266 consecutive AMI patients admitted to 22 hospitals in Hokkaido were registered. The eGFR values were determined using the following equation: eGFR $=194 \times(\text { serum creatinine })^{-1.094} \times(\text { age })^{-0.287}$ $(\times 0.739$ if female). Patients were classified into four groups according to their eGFR values: $\geqslant 60(n=1304), 30-59(n=810)$, 15-29 $(n=87)$ and $<15 \mathrm{ml} \mathrm{min}^{-1}$ per $1.73 \mathrm{~m}^{2}(n=65)$. A total of 110 patients $(4.9 \%)$ died during hospitalization. The in-hospital mortality rate was significantly higher in patients with reduced eGFR values at $2.3,5.4,24.1$ and $23.1 \%$ for eGFR values of $\geqslant 60,30-59,15-29$, and $<15 \mathrm{ml} \mathrm{min}^{-1}$ per $1.73 \mathrm{~m}^{2}$, respectively. The odds ratios for in-hospital all cause death were 8.26 (95\% confidence interval $(\mathrm{Cl}): 2.22-30.77)$ for eGFR $<15 \mathrm{ml} \mathrm{min}^{-1}$ per $1.73 \mathrm{~m}^{2}$ and $3.42(95 \% \mathrm{Cl}$ : 1.01-11.61) for eGFR $15-29 \mathrm{ml} \mathrm{min}^{-1}$ per $1.73 \mathrm{~m}^{2}$ compared with eGFR $\geqslant 60 \mathrm{ml} \mathrm{min}^{-1}$ per $1.73 \mathrm{~m}^{2}$. Similarly, the odds ratios for in-hospital cardiac death were $8.43(95 \% \mathrm{Cl}: 1.82-39.05)$ for eGFR $<15 \mathrm{ml} \mathrm{min}^{-1}$ per $1.73 \mathrm{~m}^{2}$ and $5.47(95 \% \mathrm{Cl}$ : 1.51-19.80) for eGFR $15-29 \mathrm{ml} \mathrm{min}^{-1}$ per $1.73 \mathrm{~m}^{2}$. In conclusion, the eGFR of $<30 \mathrm{ml} \mathrm{min}^{-1}$ per $1.73 \mathrm{~m}^{2}$ was a significant and independent risk for in-hospital mortality in abroad cohort of Japanese patients with AMI.

Hypertension Research (2012) 35, 463-469; doi:10.1038/hr.2011.224; published online 19 January 2012

Keywords: acute myocardial infarction; chronic kidney disease; estimated glomerular filtration rate; mortality

\section{INTRODUCTION}

Chronic kidney disease (CKD) is increasingly becoming recognized as a global public health problem. ${ }^{1}$ The National Kidney Foundation has published clinical guidelines on the evaluation, classification and risk stratification in patients with $\mathrm{CKD} .^{2}$ Despite the recognized association between a reduced estimated glomerular filtration rate (eGFR) and poor prognosis, screening for CKD is frequently limited to the measurement of serum creatinine, ${ }^{3,4}$ which does not accurately reflect the GFR. As a result, the management of this risk is often not optimized. The risks of CKD included not only the progression to end-stage renal failure but also the occurrence of adverse cardiovascular outcomes. ${ }^{5-9}$ Previous studies have demonstrated that CKD is an independent risk factor for morbidity and mortality in the general population, ${ }^{10}$ as well as in patients with cardiovascular diseases such as post acute myocardial infarction (AMI). ${ }^{11}$ Anavekar et al. ${ }^{11}$ reported that $\mathrm{CKD}$ was a common and significant independent risk factor for cardiovascular events in AMI patients based on data from the Valsartan in Acute Myocardial Infarction Trial (VALIANT). The risk was progressive, and each 10 unit reduction in the eGFR was significantly associated with a $10 \%$ increase in the relative risk of death or nonfatal cardiovascular complications. ${ }^{11}$ However, the patients in the VALIANT study had heart failure, left ventricular dysfunction, or both as a complication of AMI, and patients with a baseline serum creatinine level $>2.5 \mathrm{mg} \mathrm{dl}^{-1}$ were excluded. Therefore, the patients enrolled in the study by Anavekar et al. ${ }^{11}$ were not representative of the general AMI population routinely encountered in clinical practice. It is critically important to determine the prognostic impact of CKD in the registry data of Japanese patients with AMI.

${ }^{1}$ Department of Clinical Management and Bioinformatics, Hokkaido Information University, Hokkaido, Japan; ${ }^{2}$ Department of Cardiovascular Medicine, Hokkaido University Graduate School of Medicine, Sapporo, Japan; ${ }^{3}$ Department of Cardiovascular Medicine, NTT East Japan Sapporo Hospital, Sapporo, Japan; ${ }^{4}$ Department of Cardiovascular Medicine, Tokeidai Memorial Hospital, Sapporo, Japan and ${ }^{5}$ Department of Molecular and Cellular Pathobiology and Therapeutics, Nagoya City University Graduate School of Pharmaceutical Sciences, Nagoya, Japan

Correspondence: Dr H Satoh, Department of Clinical Management and Bioinformatics, Hokkaido Information University 59-2, Nishi-Nopporo, Ebetsu, Hokkaido 069-8585, Japan. E-mail: h-satoh@do-johodai.ac.jp

Received 19 May 2011; revised 9 October 2011; accepted 17 October 2011; published online 19 January 2012 
The aim of the present study was to examine the prognostic significance of eGFR values on the in-hospital mortality in Japanese AMI patients in routine clinical practice.

\section{METHODS}

\section{Patients}

The study patients consisted of 2266 consecutive patients hospitalized because of AMI in 22 hospitals in Hokkaido from 2005 to 2007.

AMI was defined by the presence of at least two of the following criteria: ${ }^{12-14}$ (1) a clinical history of chest pain persisting for $\geqslant 30 \mathrm{~min}$, (2) ischemic electrocardiographic changes and (3) a peak creatine kinase level equivalent to more than twice the upper limit of normal. All patients underwent coronary catheterization within $24 \mathrm{~h}$ after the onset of AMI. Body weight and height were measured in the morning after fasting. Body mass index was calculated as body weight $(\mathrm{kg})$ divided by squared height $(\mathrm{m})$. Smoking habits were determined using a self-reported questionnaire. Patients who had never smoked and exsmokers were classified as 'nonsmokers'. Hypertension was defined as a history of systolic blood pressure $\geqslant 140 \mathrm{~mm} \mathrm{Hg}$ and/or diastolic blood pressure $\geqslant 90 \mathrm{~mm} \mathrm{Hg}$ or the use of oral antihypertensive drugs. Dyslipidemia was defined as a fasting total cholesterol $\geqslant 220 \mathrm{mg}$ per $100 \mathrm{ml}$ or the use of antihypercholesterol drugs. Diabetes mellitus was defined as fasting plasma glucose $\geqslant 126 \mathrm{mg}$ per $100 \mathrm{ml}$ or the use of oral hypoglycemic drugs or insulin. Patients who had suffered from myocardial infarction and stroke were defined as 'prior cardiovascular disease'. Blood samples were obtained after an overnight fast in the hospital. The creatine kinase values were measured every $4 \mathrm{~h}$ after admission to determine the peak value. The information regarding all cause death and cardiac death during hospitalization was obtained by physicians in the hospitals where the patients were admitted. Cardiac death was defined as a death due to heart failure, fatal arrhythmia, cardiac rupture or recurrent myocardial infarction. The patient data were registered in each hospital and reported to the data management office at Hokkaido University. Written informed consent was obtained from each patient or a family member. The study protocol was approved by the ethics committee at Hokkaido University School of Medicine.

\section{Measurement of the eGFR}

To calculate the eGFR, serum creatinine was measured using the compensated Jaffe creatinine method at the time of admission to the hospital. The eGFR was calculated using the equation for Japanese as follows: ${ }^{15}$ eGFR $=194 \times($ serum creatinine $)^{-1.094} \times(\text { age })^{-0.287}(\times 0.739$ if female $) \mathrm{ml} \mathrm{min}^{-1}$ per $1.73 \mathrm{~m}^{2}$.

\section{Statistical analysis}

The characteristics of the study subjects were expressed as means \pm s.d. for continuous variables, median (and interquartile range) for skewed distribution variables, and percentages for categorical variables according to the eGFR values. The differences in variables among groups were examined by analysis of variance, Kruskal-Wallis test or chi-square test. The association between the risk factors and in-hospital deaths of AMI patients was assessed using multiple logistic regression analysis. The principal model included the following candidate variables: demographics (age, sex, body mass index, smoking, prior cardiovascular disease), medical history (hypertension, diabetes mellitus, dyslipidemia, Q wave myocardial infarction and peak creatine kinase), angiographic data (number of diseased vessels, Killip classification, thrombolysis in myocardial infarction flow grade 0 at admission and thrombolysis in myocardial infarction flow grade 3 after treatment) and procedural information (mechanical support and treatment). Variables that were regarded as significant $(P<0.05)$ were included in subgroup multivariate analyses. A $P$-value of $<0.05$ indicated statistical significance. All statistical analyses were performed using the SPSS statistical package for Windows version 11.0 (Chicago, IL, USA).

\section{RESULTS}

\section{Patient characteristics}

Figure 1 shows the distribution of the eGFR in the study patients. The mean eGFR value was $64.4 \pm 23.7 \mathrm{ml} \mathrm{min}^{-1}$ per $1.73 \mathrm{~m}^{2}$, ranging from 3.3 to $171.2 \mathrm{ml} \mathrm{min}^{-1}$ per $1.73 \mathrm{~m}^{2}$ for 2254 patients. In all, 12 patients under hemodialysis were included in the group of eGFR values

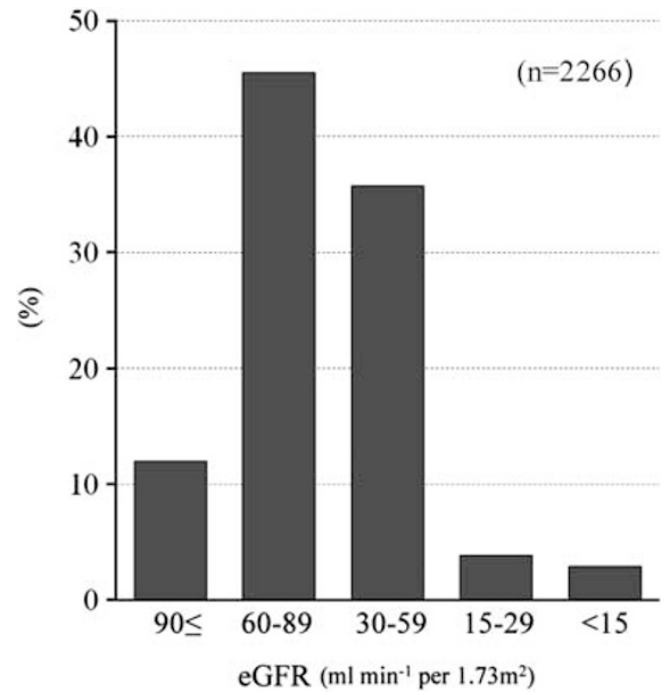

Figure 1 The distribution of the eGFR in the study patients.

$<15 \mathrm{ml} \mathrm{min}^{-1}$ per $1.73 \mathrm{~m}^{2}$. In all, $962(42.5 \%)$ patients had an eGFR $<60 \mathrm{ml} \mathrm{min}^{-1}$ per $1.73 \mathrm{~m}^{2}$ or dialysis treatment.

Table 1 shows the baseline demographic and medical characteristics of the patients according to eGFR levels. The mean age of the patients was $66 \pm 12$ years and $72.0 \%$ were men. Patients with a reduced eGFR were older and more often women. They were more likely to have hypertension, diabetes mellitus, dyslipidemia and prior cardiovascular disease.

Table 2 shows the baseline angiographic and procedural characteristics of the patients according to eGFR levels. Patients with a reduced eGFR were more likely to have severe coronary artery stenosis, severe heart failure symptoms based on Killip classifications and higher use of mechanical supports such as intraaortic balloon pumping or percutaneous cardiopulmonary support. The prevalence of thrombolysis in myocardial infarction flow grade 0 at admission and thrombolysis in myocardial infarction flow grade 3 after treatment was lower with reduced eGFR levels. The performance of percutaneous coronary intervention by stent implantation was lower and that of thrombolysis, balloon angioplasty and coronary artery bypass grafting was higher with reduced eGFR levels.

\section{Outcomes}

A total of $110(4.9 \%)$ patients died because of any causes and 84 (3.7\%) patients died because of cardiac events during hospitalization during the follow-up period of $20 \pm 17$ (2-92) days.

Table 3 shows the odds ratios and $95 \%$ confidence interval (CI) for all cause and cardiac death according to eGFR levels. The rates of all cause death were $2.3,5.4,24.1$ and $23.1 \%$ in patients with eGFR values $\geqslant 60$, $30-59,15-29$ and $<15 \mathrm{ml} \mathrm{min}^{-1}$ per $1.73 \mathrm{~m}^{2}$, respectively. The rates of cardiac death were $1.8,4.1,19.5$ and $15.4 \%$ in subjects with eGFR values $\geqslant 60,30-59, \quad 15-29$ and $<15 \mathrm{ml} \mathrm{min}^{-1}$ per $1.73 \mathrm{~m}^{2}$, respectively. Decreases in the eGFR levels were associated with a significant progressive elevation of risk for all cause $(P<0.05$ for trend) and cardiac death $(P<0.01$ for trend). By multivariate analysis with an eGFR $\geqslant 60 \mathrm{ml} \mathrm{min}^{-1}$ per $1.73 \mathrm{~m}^{2}$ as the reference, patients with eGFR of $15-29$ and $<15 \mathrm{ml} \mathrm{min}^{-1}$ per $1.73 \mathrm{~m}^{2}$ had a significantly elevated risk for all cause death (OR 3.42, 95\% CI 1.01-11.61 and OR 8.26, 95\% CI 2.2230.77 , respectively) and cardiac death (OR 5.47, 95\% CI 1.51-19.80 and OR $8.43,95 \%$ CI 1.82-39.05, respectively). By multiple logistic regression analysis, age, Killip classification $\geqslant \mathrm{II}$ at admission, prior cardio- 
Table 1 Demographic and medical characteristics of the patients according to eGFR levels

\begin{tabular}{|c|c|c|c|c|c|c|}
\hline & \multirow[b]{2}{*}{ Total $(n=2266)$} & \multicolumn{4}{|c|}{ eGFR } & \multirow[b]{2}{*}{ P-value } \\
\hline & & $\geqslant 60(n=1304)$ & $30-59(n=810)$ & $15-29(n=87)$ & $<15(\mathrm{n}=65)$ & \\
\hline Male (\%) & 72.0 & 76.5 & 67.9 & 55.2 & 56.4 & $<0.001$ \\
\hline Body mass index $\left(\mathrm{kg} \mathrm{m}^{-2}\right)$ & $24.4 \pm 3.7$ & $24.5 \pm 3.6$ & $24.3 \pm 3.5$ & $23.5 \pm 4.4$ & $24.2 \pm 6.5$ & 0.15 \\
\hline Smoking (\%) & 50.5 & 57.3 & 41.8 & 30.8 & 48.3 & $<0.001$ \\
\hline Dyslipidemia (\%) & 20.6 & 18.7 & 23.0 & 28.0 & 20.0 & $<0.05$ \\
\hline Prior cardiovascular disease (\%) & 20.7 & 16.5 & 26.1 & 26.4 & 29.7 & $<0.01$ \\
\hline Q wave myocardial infarction (\%) & 66.1 & 72.3 & 55.7 & 67.5 & 70.2 & 0.57 \\
\hline Peak creatine kinase (IU per $100 \mathrm{ml}$ ) & $2559(1441-4201)$ & $2623(1486-4275)$ & $2492(1440-4107)$ & $2505(1018-3692)$ & $2604(1112-4281)$ & 0.26 \\
\hline
\end{tabular}

Abbreviation: eGFR, estimated glomerular filtration rate.

Values are means \pm s.d., median (and interquartile range) and percentage.

Table 2 Angiographic and procedural characteristics of the patients according to eGFR levels

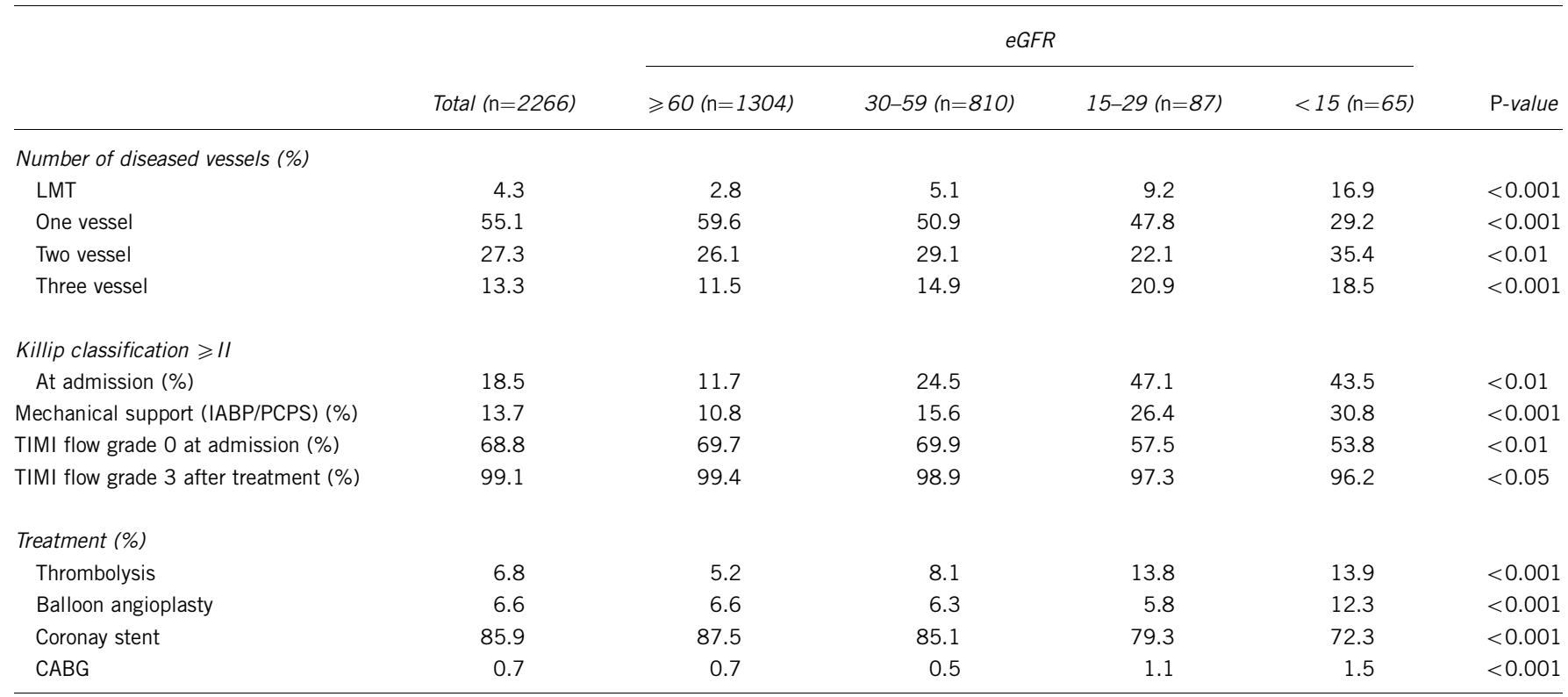

Abbreviations: CABG, coronary artery bypass grafting; eGFR, estimated glomerular filtration rate; IABP, intraaortic balloon pumping; LMT, left main trunk; PCPS, percutaneous cardiopulmonary support; TIMI, thrombolysis in myocardial infarction.

vascular disease, peak creatine kinase and eGFR values were significant and independent predictors for all cause death. Age, the use of mechanical support, peak creatine kinase and eGFR values were significant and independent predictors for cardiac death (Table 4).

Table 5 shows the results of subgroup analysis for all cause death according to eGFR levels stratified by sex, age ( $\geqslant 65 v s$. $<65$ years) and comorbidities (hypertension vs. no hypertension and diabetes mellitus $v s$. no diabetes mellitus). The eGFR $<30 \mathrm{ml} \mathrm{min}^{-1}$ per 1.73 $\mathrm{m}^{2}$ was associated with poor outcomes in each subgroup, which is in agreement with the results of the primary analysis.

\section{DISCUSSION}

The present study demonstrated that the prevalence of AMI patients with an eGFR $<60 \mathrm{ml} \mathrm{min}^{-1}$ per $1.73 \mathrm{~m}^{2}$ was $42.5 \%$ based on a largescale, multicenter trial. A reduced eGFR was a significant and independent risk for in-hospital all-cause and cardiac mortality. Moreover, AMI patients with eGFR values $<30 \mathrm{ml} \mathrm{min}^{-1}$ per 1.73 $\mathrm{m}^{2}$ had a significantly greater mortality risk than patients with values $\geqslant 60 \mathrm{ml} \mathrm{min}^{-1}$ per $1.73 \mathrm{~m}^{2}$.

Previous studies used serum creatinine levels rather than the eGFR to detect renal dysfunction. ${ }^{3,4}$ However, the accuracy of serum creatinine levels is limited as a marker of renal function because significant kidney dysfunction can be present despite a normal serum creatinine concentration. Serum creatinine has a nonlinear association with eGFR according to age, sex and lean body mass. ${ }^{16,17}$ The National Kidney Foundation ${ }^{2}$ and Kidney Disease Improving Global Outcomes $(\mathrm{KDIGO})^{18}$ have recommended using an eGFR estimated by serum creatinine, and eGFR $<60 \mathrm{ml} \mathrm{min}^{-1}$ per $1.73 \mathrm{~m}^{2}$ is selected as the cutoff value for the diagnosis of CKD. The eGFR values were generally estimated by the modification of diet in renal disease or creatinine clearance. Imai et al. ${ }^{19}$ reported that the modification of diet in renal disease equation might overestimate the GFR in Japanese populations compared with the GFR measured using insulin clearance. Matsuo et al..$^{15}$ demonstrated that the accuracy of the eGFR estimation was 
Table 3 The odds ratios and $95 \% \mathrm{Cl}$ for all cause and cardiac death according to eGFR values

\begin{tabular}{|c|c|c|c|c|c|}
\hline & \multicolumn{4}{|c|}{ eGFR } & \multirow[b]{2}{*}{$P$ for treno } \\
\hline & $\geqslant 60(n=1304)$ & $30-59(n=810)$ & $15-29(n=87)$ & $<15(\mathrm{n}=65)$ & \\
\hline $\mathrm{n}(\%)$ & $30(2.3)$ & $44(5.4)$ & $21(24.1)$ & $15(23.1)$ & \\
\hline Model 1 , odds ratio $(95 \% \mathrm{Cl})$ & 1.00 & $1.66(1.01-2.73)$ & $7.58(3.95-14.53)$ & $10.64(5.31-21.30)$ & $<0.001$ \\
\hline Model 2 , odds ratio $(95 \% \mathrm{Cl})$ & 1.00 & $1.58(0.99-2.81)$ & $6.24(3.03-12.85)$ & 9.55 (4.39-20.77) & $<0.001$ \\
\hline \multicolumn{6}{|l|}{ Cardiac death } \\
\hline$n(\%)$ & $24(1.8)$ & $33(4.1)$ & $17(19.5)$ & $10(15.4)$ & \\
\hline Model 1 , odds ratio $(95 \% \mathrm{Cl})$ & 1.00 & $1.52(0.87-2.67)$ & $7.49(3.67-15.29)$ & $8.90(4.01-20.00)$ & $<0.001$ \\
\hline Model 2, odds ratio $(95 \% \mathrm{Cl})$ & 1.00 & $1.46(0.85-2.52)$ & $7.10(3.31-15.20)$ & $8.88(3.74-21.04)$ & $<0.001$ \\
\hline Model 3 , odds ratio $(95 \% \mathrm{Cl})$ & 1.00 & $1.02(0.41-2.53)$ & $5.47(1.51-19.80)$ & $8.43(1.82-39.05)$ & $<0.01$ \\
\hline
\end{tabular}

Table 4 Multivariate predictors of outcomes by multiple logistic regression analysis

\begin{tabular}{|c|c|c|c|}
\hline & Odds ratio & $95 \% \mathrm{Cl}$ & P-value \\
\hline \multicolumn{4}{|l|}{ All cause death } \\
\hline Age (per 1 year increase) & 1.06 & $1.02-1.10$ & $<0.01$ \\
\hline Prior cardiovascular disease & 2.21 & $1.02-4.79$ & $<0.05$ \\
\hline Peak creatine kinase (per $100 \mathrm{IU}$ per $100 \mathrm{ml}$ increase) & 1.02 & $1.01-1.03$ & $<0.01$ \\
\hline eGFR (per $10 \mathrm{ml} \mathrm{min}^{-1}$ per $1.73 \mathrm{~m}^{2}$ decrease) & 1.36 & $1.14-1.62$ & $<0.01$ \\
\hline Age (per 1 year increase) & 1.06 & $1.02-1.10$ & $<0.01$ \\
\hline Mecanical support (IABP/PCPS) & 3.51 & $1.39-8.84$ & $<0.01$ \\
\hline Peak creatine kinase (per $100 \mathrm{IU}$ per $100 \mathrm{ml}$ increase) & 1.01 & $1.01-1.02$ & $<0.05$ \\
\hline eGFR (per $10 \mathrm{ml} \mathrm{min}^{-1}$ per $1.73 \mathrm{~m}^{2}$ decrease) & 1.37 & $1.13-1.68$ & $<0.01$ \\
\hline
\end{tabular}

Abbreviations: $\mathrm{CI}$, confidence interval; eGFR, estimated glomerular filtration rate; IABP, intraaortic balloon pumping; PCPS, percutaneous cardiopulmonary support.

Adjusted for demographic (age and sex), medical (body mass index, smoking, hypertension, diabetes mellitus, dyslipidemia, prior cardiovascular disease, $Q$ wave myocardial infarction, peak creatine kinase and eGFR), angiographic (number of diseased vessles and killip classification $\geqslant I I$ ) and procedural (mechanical support, TIMI (thrombolysis in myocardial infarction) flow grade 0 at admission and TIMI flow grade 3 after treatment) variables.

more improved using the new Japanese equation rather than using the modification of diet in renal disease equation in Japanese populations. Therefore, the present study used the new Japanese equation to calculate the eGFR values.

Previous studies demonstrated that $\mathrm{CKD}$ is an independent risk factor for cardiovascular disease in the general population in Japan..$^{20,21}$ Anavekar et al. ${ }^{11}$ showed that the prevalence of CKD patients suffering from AMI in Western countries was 33.5\%, and Nakamura et al. ${ }^{22}$ reported that it was $31.6 \%$ in Japanese patients with coronary artery disease. The prevalence of CKD in the present study was $42.4 \%$, which is higher than the rates reported in previous studies. ${ }^{11,22}$ These discrepancies may be partially explained by the differences in ethnicity and other risk factors such as age and obesity. More importantly, the registry used in this study enrolled all patients that were admitted to the hospital because of AMI and did not exclude those who had higher levels of serum creatinine or dialysis treatment. Thus, the patients in the present study had a high prevalence of renal dysfunction and were considered to be more reflective of current routine clinical practice.

The present study extended the previous studies and demonstrated the prognostic significance of reduced eGFR in patients with coronary artery disease. . $^{30,20,21,23-28}$ The Atherosclerosis Risk in Communities (ARIC) study ${ }^{23}$ and the Second National Health and Nutrition Examination Survey (NHANES II) ${ }^{3}$ demonstrated that a mild reduction in eGFR was a significant risk factor for both coronary vascular disease and all-cause mortality. The present study confirmed the prior studies by Anavekar et al. in which reduced eGFR was independently associated with an increased risk of fatal and nonfatal adverse cardiovascular events after AMI. ${ }^{11}$ However, in their study, the study patients were limited to have baseline serum creatinine levels $<2.5 \mathrm{mg} \mathrm{dl}^{-1}$ and heart failure. In addition, only $20 \%$ of the patients were treated with percutaneous coronary intervention. Thus, the impact of CKD has not been elucidated in a representative cohort of patients receiving contemporary therapy for AMI. To examine the 
Table 5 Subgroup analysis for all cause death according to eGFR levels

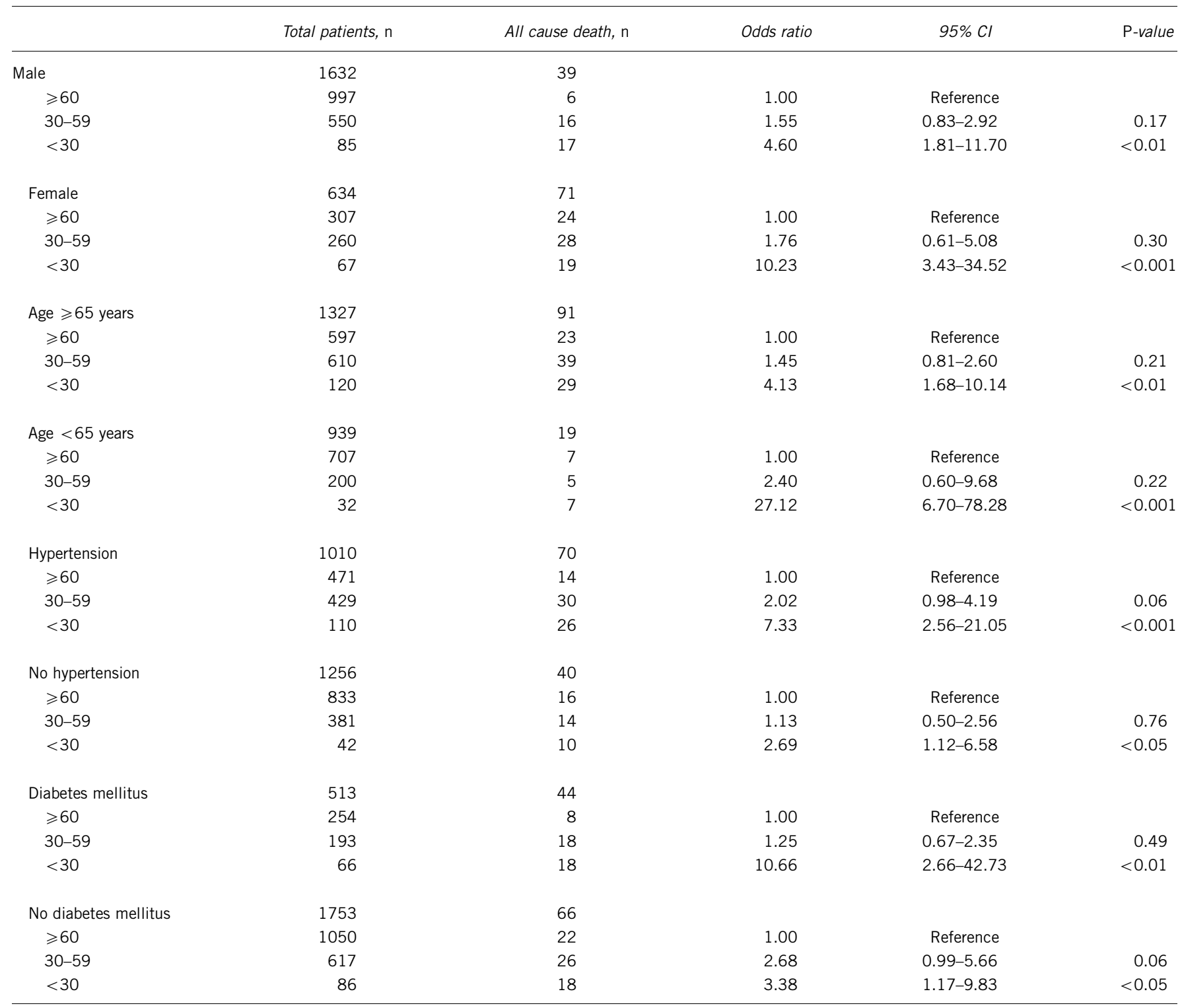

Abbreviations: $\mathrm{Cl}$, confidence interval; eGFR, estimated glomerular filtration rate.

Adjusted for demographic (age and sex), medical (body mass index, smoking, hypertension, diabetes mellitus, dyslipidemia, prior cardiovascular disease, $Q$ wave myocardial infarction and peak creatine kinase), angiographic (number of diseased vessles and killip classification $\geqslant I I$ ) and procedural (mechanical support, TIMI (thrombolysis in myocardial infarction) flow grade 0 at admission and TIMI flow grade 3 after treatment) variables.

impact of eGFR in AMI and to determine whether it is independently associated with prognosis, we analyzed data from a prospective broad cohort of patients with AMI. The patients in the present study had baseline serum creatinine levels ranging from 0.3 to $12.6 \mathrm{mg} \mathrm{dl}^{-1}$, and percutaneous coronary intervention was performed in $92.5 \%$ of the patients during the acute phase. We thus could extend the prognostic impact of CKD from selected patients in large-scale clinical trials to a diverse cohort of AMI patients in general. Kasai et al. ${ }^{29}$ demonstrated that lower eGFR values were significant long-term predictors for allcause and cardiac mortality in Japanese patients who underwent complete coronary revascularization using a 10-year cohort study. The present study also confirmed these findings. Although the present study included both patients that underwent complete and incomplete coronary revascularization, adjustments for this variable were included in the statistical analysis. As a result, the findings in this study might be more applicable to a general population.

The present study demonstrated that the significant risk factors differed depending on the outcomes such as all cause and cardiac death (Table 4). There are potential explanations for these findings. Cardiac death was defined as death due to heart failure, fatal arrhythmia, cardiac rupture and recurrent myocardial infarction. In contrast, all cause death included not only cardiac death but also other causes of death such as infection. Killip classification and prior cardiovascular disease were independent predictors for all cause death, suggesting that heart failure associated with AMI might induce systemic organ failure and other complications leading to death. Mechanical support was an independent predictor for cardiac death, indicating that severe circulatory shock associated with 
AMI may result in cardiac death, including fatal arrhythmia and cardiac rupture.

There are several possible explanations by which CKD increases the in-hospital mortality in patients with AMI. CKD may be indicative of traditional risk factors such as older age, hypertension, dyslipidemia and diabetes mellitus, which have been established to be closely related to cardiovascular outcomes. ${ }^{30}$ Therefore, CKD may reflect the presence of severe coronary artery disease. Even after adjustments for demographic, medical, angiographic and procedural variables, the eGFR remained a significant risk for in-hospital all-cause and cardiac mortality. The increase in mortality with a reduced eGFR can be partly explained by nontraditional factors associated with $\mathrm{CKD}$, including increased inflammatory factor levels, ${ }^{31}$ elevated homocysteine levels, ${ }^{32}$ enhanced coagulability ${ }^{31}$ and endothelial dysfunction, ${ }^{33}$ which were not assessed in this study.

\section{Study limitations}

First, we only assessed the baseline eGFR and could not determine the effects of changes in eGFR on outcomes. Second, the present study did not collect data regarding the use of medication after hospitalization because it varies widely among patients according to their clinical status, especially during the acute phase of AMI. However, the use of medication may affect the outcomes of patients during the long-term follow-up. Third, information was not collected during the follow-up after discharge, and the impact of CKD on the long-term outcomes in AMI patients could not be assessed. Fourth, coronary catheterization was performed after the onset of AMI in all patients, but severe patients who could not undergo coronary catheterization were not included. Therefore, the present results cannot be applied to all patients with AMI in general.

\section{CONCLUSION}

The reduced eGFR was a significant and independent risk for in-hospital all-cause and cardiac mortality in a broad cohort of Japanese patients hospitalized with AMI. Evaluation of renal function and effective management of these high-risk patients with AMI is important.

\section{ACKNOWLEDGEMENTS}

Participating hospitals and investigators for the Hokkaido Acute Myocardial Infarction Registry are as follows: Teisuke Anzai (Hokkaido Cardiovascular Center, National Hospital Organization Hakodate Hospital), Naoya Matsumura, Yasuhiro Makita (Hakodate Municipal Hospital), Hiroshi Asajima, Naotaka Saito (Hakodate Central General Hospital), Sigeru Takechi (Date Red Cross Hospital), Masaharu Machida (Tomakomai City Hospital), Takashi Shogase, Hitoshi Okada, Satoru Chiba (Nikko Memorial Hospital), Takefumi Ozaki (Chitose City Hospital), Junichi Teranishi (Nishi Sapporo National Hospital), Noriyoshi Kato, Yasumi Igarashi (Sapporo City General Hospital), Kouichi Kanda (Sapporo-Kosei General Hospital), Kazuo Tomita, Tetsuro Koya (NTT East Japan Sapporo Hospital), Toshiaki Nakagawa, Takehiro Yamashita, Toru Morita (Cardio-vascular Center Hokkaido Ohno Hospital), Masayuki Sakurai, Katsuhiko Sato, Yasushi Takagi (Hokko Memorial Hospital), Eiichiro Imamura (Ogasawara Clinic, Sapporo Hospital), Sigeo Kakinoki, Cika Takagi (Otaru Kyokai Hospital), Hisashi Matsuo (Keiwakai Ebetsu Hospital), Hideyuki Takano, Mitsunori Otsubo (Hokkaido Chuo Rosai Hospital), Isao Sato (Hokkaido Chuo Rosai Hospital Spinal Cord Injury Center), Takayuki Hirabayashi, Motoi Sasaki (Sunagawa City Medical Center), Yutaka Yamada (Asahikawa City Hospital), Yuta Nakagawa, Hiroyuki Iwano, Kagami Hirabayashi (Kitami Red Cross Hospital), Hidetsugu Sakai (Kushiro Rosai Hospital), Tomoharu Nakamura (Kushiroshi-Ishikai Hospital), Masashige Takahashi (Wakkanai City Hospital) and Ichiro Yoshida (Hokuto Medical Corporation Hokuto Hospital).
1 Foley RN, Parfrey PS, Sarnak MJ. Clinical epidemiology of cardiovascular disease in chronic renal disease. Am J Kidney Dis 1998; 32: S112-S119.

2 National Kidney Foundation. K/DOQI clinical practice guidelines for chronic kidney disease: evaluation, classification, and stratification. Am J Kidney Dis 2002; 39: S1-266.

3 Culleton BF, Larson MG, Wilson PW, Evans JC, Parfrey PS, Levy D. Cardiovascular disease and mortality in a community-based cohort with mild renal insufficiency. Kidney Int 1999; 56: 2214-2219.

4 Garg AX, Clark WF, Haynes RB, House AA. Moderate renal insufficiency and the risk of cardiovascular mortality: results from the NHANES I. Kidney Int 2002; 61: 1486-1494.

5 Fukuta H, Ohte N, Mukai S, Asada K, Wakami K, Goto T, Kimura G. Relationship between renal function, aortic stiffness and left ventricular function in patients with coronary artery disease. Circ J 2009; 73: 1740-1745.

6 Hamaguchi S, Tsuchihashi-Makaya M, Kinugawa S, Yokota T, Ide T, Takeshita A, Tsutsui $\mathrm{H}$. Chronic kidney disease as an independent risk for long-term adverse outcomes in patients hospitalized with heart failure in Japan. Report from the Japanese Cardiac Registry of Heart Failure in Cardiology (JCARE-CARD). Circ J 2009; 73: 1442-1447.

7 Koganei $\mathrm{H}$, Kasanuki $\mathrm{H}$, Ogawa $\mathrm{H}$, Tsurumi Y. Association of glomerular filtration rate with unsuccessful primary percutaneous coronary intervention and subsequent mortality in patients with acute myocardial infarction: from the HIJAMI registry. Circ J 2008; 72: 179-185.

8 Komukai K, Ogawa T, Yagi H, Date T, Sakamoto H, Kanzaki Y, Shibayama K, Hashimoto K, Inada K, Minai K, Ogawa K, Kosuga T, Kawai M, Hongo K, Taniguchi I, Yoshimura M. Decreased renal function as an independent predictor of re-hospitalization for congestive heart failure. Circ J 2008; 72: 1152-1157.

9 Levey AS, Coresh J, Balk E, Kausz AT, Levin A, Steffes MW, Hogg RJ, Perrone RD, Lau J, Eknoyan G. National Kidney Foundation practice guidelines for chronic kidney disease: evaluation, classification, and stratification. Ann Intern Med 2003; 139: 137-147.

10 Go AS, Chertow GM, Fan D, McCulloch CE, Hsu CY. Chronic kidney disease and the risks of death, cardiovascular events, and hospitalization. N Engl J Med 2004; 351: 1296-1305.

11 Anavekar NS, McMurray JJ, Velazquez EJ, Solomon SD, Kober L, Rouleau JL, White HD, Nordlander R, Maggioni A, Dickstein K, Zelenkofske S, Leimberger JD, Califf RM, Pfeffer MA. Relation between renal dysfunction and cardiovascular outcomes after myocardial infarction. N Engl J Med 2004; 351: 1285-1295.

12 WHO Expert Comittee. Arterial Hypertension and Ischemic Disease Preventive Aspects. WHO Technical Report Series: Geneva, 1962 No231.

13 Tunstall-Pedoe H, Kuulasmaa K, Amouyel P, Arveiler D, Rajakangas AM, Pajak A. Myocardial infarction and coronary deaths in the World Health Organization MONICA Project. Registration procedures, event rates, and case-fatality rates in 38 populations from 21 countries in four continents. Circulation 1994; 90: 583-612.

14 Thygesen K, Alpert JS, White HD, Jaffe AS, Apple FS, Galvani M, Katus HA, Newby LK, Ravkilde J, Chaitman B, Clemmensen PM, Dellborg M, Hod H, Porela P, Underwood R, Bax JJ, Beller GA, Bonow R, Van der Wall EE, Bassand JP, Wijns W, Ferguson TB, Steg PG, Uretsky BF, Williams DO, Armstrong PW, Antman EM, Fox KA, Hamm CW, Ohman EM, Simoons ML, Poole-Wilson PA, Gurfinkel EP, Lopez-Sendon JL, Pais P, Mendis S, Zhu JR, Wallentin LC, Fernandez-Aviles F, Fox KM, Parkhomenko AN, Priori SG, Tendera M, Voipio-Pulkki LM, Vahanian A, Camm AJ, De Caterina R, Dean V, Dickstein K, Filippatos G, Funck-Brentano C, Hellemans I, Kristensen SD, McGregor K, Sechtem U, Silber S, Widimsky P, Zamorano JL, Morais J, Brener S, Harrington R, Morrow D, Lim M, Martinez-Rios MA, Steinhubl S, Levine GN, Gibler WB, Goff D, Tubaro M, Dudek D, Al-Attar N. Universal definition of myocardial infarction. Circulation 2007; 116: 2634-2653.

15 Matsuo S, Imai E, Horio M, Yasuda Y, Tomita K, Nitta K, Yamagata K, Tomino Y, Yokoyama $\mathrm{H}$, Hishida A. Revised equations for estimated GFR from serum creatinine in Japan. Am J Kidney Dis 2009; 53: 982-992.

16 Al Suwaidi J, Reddan DN, Williams K, Pieper KS, Harrington RA, Califf RM, Granger CB, Ohman EM, Holmes Jr DR. Prognostic implications of abnormalities in renal function in patients with acute coronary syndromes. Circulation 2002; 106: 974-980.

17 Shlipak MG. Pharmacotherapy for heart failure in patients with renal insufficiency. Ann Intern Med 2003; 138: 917-924.

18 Levey AS, Eckardt KU, Tsukamoto Y, Levin A, Coresh J, Rossert J, De Zeeuw D, Hostetter TH, Lameire N, Eknoyan G. Definition and classification of chronic kidney disease: a position statement from Kidney Disease: Improving Global Outcomes (KDIGO). Kidney Int 2005; 67: 2089-2100.

19 Imai E, Horio M, Nitta K, Yamagata K, Iseki K, Tsukamoto Y, Ito S, Makino H, Hishida A, Matsuo S. Modification of the Modification of Diet in Renal Disease (MDRD) Study equation for Japan. Am J Kidney Dis 2007; 50: 927-937.

20 Ninomiya T, Kiyohara Y, Kubo M, Tanizaki Y, Doi Y, Okubo K, Wakugawa Y, Hata J, Oishi Y, Shikata K, Yonemoto K, Hirakata H, lida M. Chronic kidney disease and cardiovascular disease in a general Japanese population: the Hisayama Study. Kidney Int 2005; 68: 228-236.

21 Kokubo Y, Nakamura S, Okamura T, Yoshimasa Y, Makino H, Watanabe M, Higashiyama A, Kamide K, Kawanishi K, Okayama A, Kawano Y. Relationship between blood pressure category and incidence of stroke and myocardial infarction in an urban Japanese population with and without chronic kidney disease: the Suita Study. Stroke 2009; 40: 2674-2679.

22 Nakamura M, Yamashita T, Yajima J, Oikawa Y, Ogasawara K, Kirigaya H, Sagara K, Koike A, Sawada H. Aizawa T. Impact of reduced renal function on prognosis in Japanese patients with coronary artery disease: a prospective cohort of Shinken Database 2007. Hypertens Res 2009; 32: 920-926. 
23 Manjunath G, Tighiouart H, Ibrahim H, MacLeod B, Salem DN, Griffith JL, Coresh J, Levey AS, Sarnak MJ. Level of kidney function as a risk factor for atherosclerotic cardiovascular outcomes in the community. J Am Coll Cardiol 2003; 41: 47-55.

24 Zhang L, Zuo L, Wang F, Wang M, Wang S, Lv J, Liu L, Wang H. Cardiovascular disease in early stages of chronic kidney disease in a Chinese population. J Am Soc Nephrol 2006; 17: 2617-2621.

25 Blackman DJ, Pinto R, Ross JR, Seidelin PH, Ing D, Jackevicius C, Mackie K, Chan C, Dzavik V. Impact of renal insufficiency on outcome after contemporary percutaneous coronary intervention. Am Heart J 2006; 151: 146-152.

26 Cooper WA, O'Brien SM, Thourani VH, Guyton RA, Bridges CR, Szczech LA, Petersen R, Peterson ED. Impact of renal dysfunction on outcomes of coronary artery bypass surgery: results from the Society of Thoracic Surgeons National Adult Cardiac Database. Circulation 2006; 113: 1063-1070.

27 Holzmann MJ, Hammar N, Ahnve S, Nordqvist T, Pehrsson K, Ivert T. Renal insufficiency and long-term mortality and incidence of myocardial infarction in patients undergoing coronary artery bypass grafting. Eur Heart J 2007; 28 865-871.
28 Kangasniemi OP, Mahar MA, Rasinaho E, Satomaa A, Tiozzo V, Lepojarvi M, Biancari F. Impact of estimated glomerular filtration rate on the 15-year outcome after coronary artery bypass surgery. Eur J Cardiothorac Surg 2008; 33: 198-202.

29 Kasai T, Miyauchi K, Kajimoto K, Kubota N, Dohi T, Tsuruta R, Ogita M, Yokoyama T, Amano A, Daida H. Prognostic significance of glomerular filtration rate estimated by the Japanese equation among patients who underwent complete coronary revascularization. Hypertens Res 2010; 34: 378-383.

30 Wilson PW, D'Agostino RB, Levy D, Belanger AM, Silbershatz H, Kannel WB. Prediction of coronary heart disease using risk factor categories. Circulation 1998; 97: 1837-1847.

31 Shlipak MG, Fried LF, Crump C, Bleyer AJ, Manolio TA, Tracy RP, Furberg CD, Psaty BM. Elevations of inflammatory and procoagulant biomarkers in elderly persons with renal insufficiency. Circulation 2003; 107: 87-92.

32 Muntner P, Hamm LL, Kusek JW, Chen J, Whelton PK, He J. The prevalence of nontraditional risk factors for coronary heart disease in patients with chronic kidney disease. Ann Intern Med 2004; 140: 9-17.

33 Blacher J SM, Guerin AP, Pannier B, Marchais SJ, London GM. Aortic pulse wave velocity index and mortality in end-stage renal disease. Kidney Int 2003; 63 : $1852-1860$ 